\title{
Raúl Porras y la conquista del Perú*
}

\author{
WALDEMAR ESPINOZA SORIANO
}

Asistimos esta noche a la presentación del libro titulado Literatura, historia e ideología en la biografía de Francisco Pizarro (Lima 1992, 137 p.), cuyo autor es Edmundo Bendezú Aibar, editado por Luis Arriola Ricaldi y Miguel Angel Rodríguez Rea, fundadores y directores de la Colección Prisma.

Bendezú, como él mismo lo expresa, ha venido indagando sobre la biografía de Pizarro desde 1954, año en que ingresó a la Universidad Mayor de San Marcos, en el cual fue alumno de Raúl Porras Barrenechea. A partir de entonces, poco a poco con método y cordura fue acumulando y estudiando toda la bibliografía accesible en el Perú sobre el conquistador en referencia, entre cuyos textos, como es racional, no podían faltar los que nos dictó el eminente historiador Raúl Porras. De manera que mientras en la primera parte de su libro Bendezú nos habla de los artículos, folletos y libros publicados antes, durante y después de la vida de Porras; en cambio en la que podemos llamar la segunda parte nos brinda el análisis acucioso de las 490 páginas de las copias mecanográficas del volumen Francisco Pizarro el Fundador, que dejó Porras reunidos en dos tomos. El contenido de las carillas de Bendezú constituye un texto coherente, limpio, muy bien escrito. Es la historia de los hallazgos documentales hechos por Porras Barrenechea en el Perú pero primordialmente en España, y de cómo el preclaro maestro llevó a cabo esas investigaciones para reconstituir el vivir de Pizarro.

* Texto leído el 20 de julio de 1992, en el Auditorio del Banco Continental, en Lima. 
Al trabajo de Edmundo lo encuentro escrupuloso y penetrante. Se ve que ha averiguado en muchísimas fuentes, desde las más modestas a las más encumbradas. En tal aspecto, me parece que no le falta nada de lo esencial.

\section{La leyenda dorada de Pizarro}

La gran pasión de Raúl Porras fue escribir la historia completa de la conquista del Perú, a la que él, con toda razón, identificaba con la vida y acciones de Francisco Pizarro. Con tal objetivo realizó tareas de heurística y hemenéutica en los aarchivos y bibliotecas del Perú. Le tenía tanta admiración que estaba decidido a componer su biografía y con ella a crear y desarrollar la leyenda dorada sobre el conquistador del país de los incas. Con aquella finalidad, desde 1929 comenzó a releer y estudiar a los cronistas. En 1935 aparecen sus primeros artículos referentes al capitán trujillano, reclamando la erección de un monumento a este personaje que, según su entender, fue el fundador de la nación peruana. Claro que el monumento llegó a materializarse, pero no por decisión del gobierno peruano sino como regalo de una dama norteamericana admiradora de Pizarro.

Luego fue a España a investigar. En 1936 șe hallaba en París y Viena con las mismas intenciones. En el citado año fue que editó el Testamento de Pizarro. Eró939 9 regreso a Espana," inmediatamente del triunfo de Franco, para proseguir la biografía del conquistador del Perú. Continuamente corregía y ampliaba sus borradores. Y por fin retornó a Sevilla, donde hizo público su hispanismo. En la capital andaluza estuvo hasta 1940. Enseguida viajó a los archivos de Trujillo de Extremadura. Y allí ubicó la casa donde nació Pizarro, en los arrabales de la ciudad y no en el solar de la hidalga familia de su progenitor, como se creía hasta la fecha.

Porras ya, como Riva-Agüero también, exaltaban las proezas del destructor del Tahuantinsuyo. Ambos lo calificaban de "fundador del Perú". Pero Raúl Porras es quien lo presentaba como el arquetipo del imperio español. O dicho de otro modo, como el hombre ejemplar para la juventud por su osadía, serenidad y bondad. He ahí por qué repetidamente le llamaba "Pizarro el Bueno", gran caballero y hombre 
heroico; dando la sensación de no ser un biógrafo equilibrado. De ahí que poco le faltó para darle calificativo de "hombre-dios" a su héroe predilecto; cosa que sí lo hizo años después el escritor Waldo de Mier en su libro La ruta de los conquistadores (1959), en cuyas líneas nombra a Extremadura tierra donde nacian los dioses.

En consecuencia, de conformidad a los juicios de Porras, la invasión y conquista del imperio de los Incas fue la más honrosa del mundo, por haber estado hecha bajo el influjo de las ideas lascasianas, lo que Raúl Porras pretendía probar con el uso que se hizo en Cajamarca del famoso requerimiento. Agregando que hasta que no llegó Pedro de Alvarado en 1534 la invasión y conquista fue pacífica, sin saqueos o "rancheamientos".

Aquí yo percibo que Porras exageraba la cuestión de salvar a Pizarro. En lo que toca al traslado de la ciudad de Jauja al valle de Lima, asevera que fue para defender a los indios de la costa que tenían que cargar trabajosamente los tributos hasta las alturas jaujinas. Sin embargo, lo que imperó con más fuerza y evidencia fue el deseo de no perder de vista el mar para controlar y repelar con facilidad a cualquier intruso que anhelara invadir y apoderarse de algún sector de la gobernación de Pizarro, como ya lo había ansiado Pedro de Alvarado en esos días.

\section{Biblioteca de Letras}

En tal sentido,"Porras aprovechaba todo dato posible para demostrar que Pizarro fue un conquistador humano y bondadoso con los indios. Manifestó que con tal fin hasta conmutó la pena de la hoguera por la de garrote para aliviar la muerte de Atahualpa. Añadiendo que no fue un jefe codicioso, por cuanto jamás acumuló riquezas. Llegando a concluir de que a Pizarro hay que recordarlo no por sus hazañas de conquistador, sino como fundador de ciudades, todas las cuales siguen vigentes en el Perú, Ecuador y Bolivia.

Yo, como Bendezú, también hallo, pues, que Porras eludía los excesos de Pizarro. No menciona ni comenta, por ejemplo, que él mandó asesinar a Cura Ocllo y decretó matar al Villahumo. La verdad es que Pizarro fue un conquistador cruel como los demás. No hay que soslayar de que su vida transcurrió en medio de una época de guerra y no en un Estado de derecho. Así hay que comprenderlo. 
Porras daba, por lo tanto, la impresión de ser un historiador subjetivo, eminentemente cuando trataba de reivindicar a Pizarro; para lo cual idealizaba la Conquista. Así logró atenuar la política de terror que el trujillano aplicó en el Perú desde un principio, como cuando ordenó quemar a los curacas tallanes de Tangarará; o cuando disimuló el genocidio cometido por Francisco de Chávez en Conchucos, etnia en la que dirigió la matanza de 600 criaturas para de esa manera escarmentar a sus padres que se negaban a entregar tributos excesivos a su encomendero. Y también frente a Benalcázar cuando dispuso y presenció la masacre de 3,000 niños y mujeres en El Quinche, porque sus padres y esposas se resistían a revelar los depósitos de metales preciosos.

Para Porras, sin embargo, los incas habían sido mas feroces que los españoles. Memora cabalmente que Atahualpa bebía chicha en el cráneo de su hermano Atoc y convertía en tambores a los cuerpos de sus enemigos. De manera que Pizarro y sus soldados, en comparación con los otros, aparecen como héroes civilizadores y libertadores. En tal aspecto, justifica el proceso contra Atahualpa. Sostiene que Pizarro no conocía de leyes, y que rubricó la sentencia presionado por los almagristas y por el propio fray Vicente Valverde. Al fin, lo que hacía es defender las conquistas llevadas a efecto por dos llamados "pueblos superiores".

Como se notará, Porras por entonces era un auténtico hispanis"Jorge Puccinelli Converso"

ta, no cansándose de considerar y manifestar que la connquista del Perú fue la más piadosa de América.

Pondera con elogios las Ordenanzas que emitió Pizarro en el Cusco para el buen tratamiento de los indios, pese a que desde el día de su promulgación fueron letra muerta, ya que nunca fueron cumplidas aunque sí acatadas. Justamente las tropelías cometidas por los españoles estimularon la guerra de Manco Inca, que duró ocho años.

También noto que cuando describe las gestas de la conquista lo hace como si hubiera sido uno de sus protagonistas. Estaba tan unificado con ellos que a cualquiera de las desgracias y/o éxitos españoles los menciona como si los habría sentido en carne propia. Esto es muy notorio cuando habla de la victoria de Quisquis en Vilcacunga. 
Sus conceptos sobre la Conquista, Porras Barrenechea los exteriorizaba en las aulas de San Marcos. Pero lo que le dio celebridad nacional e internacional fue su discurso que pronunció en la Academia Peruana de la Lengua correspondiente de la de Madrid, jornada en la que fue incorporado a dicha institución. Fue la noche del 26 de junio de 1941: 400 aniversario del asesinato de Francisco Pizarro. El referido evento fue llevado a cabo a sugerencia del entonces presidente del Perú, don Manuel Prado, quien lo efectivizó a través del presidente del Consejo de Ministros, doctor Solf y Muro. La Academia estaba presidida en esos momentos por José de la Riva-Agüero, quien encomió los trabajos e ideas de Porras, aunándose a la apología en honor a Pizarro. En realidad, la mencionada conferencia fue organizada con el cáracter de vindicatoria para los invasores y conquistadores del Tahuantinsuyo. Fue transmitida a nivel nacional mediante las ondas de la radio estatal, posibilitando ser escuchada por una audiencia de miles de peruanos. Ahí fue cuando, al diferenciar la vida de Pizarro de la de Hernán Cortes, Portas teyó una de las más brillantes páginas de sicología comparada.

Por otra parte, quedó definitivamente aclarado que Diego de Almagro jamás despertó su fascinación e interés. Siempre, a partir de entonces, cada vez que do citabarque fueron muchas veces, era para denigrarlo y afearlo, y no solamente a él sino a todos sus adeptos, sin percatarse de que la primera guerra civil, como recalca Bendezú en su ensayo, fue una lucha de clases: de pobres y desposeídos contra los ricos pizarristas, $y$ viceversa.

Al finalizar Porras su discurso sobre Pizarro el Fundador fue aplaudido a rabiar en el Teatro Segura por el presidente del Perú, ministros, embajadores, por el arzobispo y una inmensa cantidad de representantes de la aristocracia y burguesía limeña, pues no dejaron entrar a otra gente.

De esa manera el presidente Prado, en 1941, dejó oficializado el hispanismo y la admiración a Pizarro. Los hispanistas de aquellos años pensaban que el destino y el futuro de nuestra patria dependía de la asimilación del indio a la cultura occidental. $\mathrm{O}$ en otras palabras, del olvido de las costumbres andinas por arcaicas e inútiles. 


\section{La apoteosis de Pizarro}

El largo capítulo "Pizarro" que Edmundo Bendezú estudia ahora, Porras lo escribió antes de 1948. Esto se deduce de las propias declaraciones de su autor cuando habla de Diego de Trujillo mencionándolo como a "cronista inédito" todavía. La primera edición de Trujillo data precisamente de 1948. Lo que quiere decir que fue hacia 1947 que el maestro sanmarquino detuvo su redacción de la vida de Pizarro, dedicándose a otros manuales y artículos. A partir de entonces sólo iba a publicar algunos fragmentos de la aludida biografía, en tanto ejercía la embajada del Perú en España.

Las biografías referentes a Pizarro pasan de 30 . Pero las que sobresalen son pocas; y entre éstas figura en sitial preferente la pergeñada por Porras, que, si bien inacabada ofrece abundantes informes sobre aspectos ignorados hasta esos años, aparte de deliciosos párrafos concernientes a la personalidad y psicología del mismo y de otros personajes, de Almagro por ejemplo. En el enorme fólder que dejó inédito (y que sólo sería publicado en 1978, a más de 18 años del fallecimiento de su autor), Porras otra vez exalta y redimensiona la existencia de Pizarro, trazando la apoteosis de este capitán, para lo cual dio rienda suelta a su hispanismo

En este generosistimotexto, como acostumbraba, puso mucho

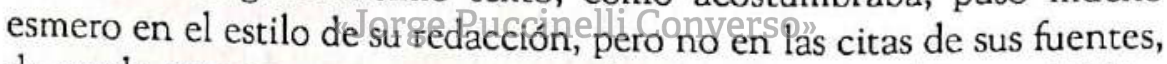
de modo que no conocemos puntualmente en qué archivos y bibliotecas descansan los centenares de informes que revela. No es que Porras haya carecido de sentido y preparación bibliográfica. Lo que ocurre es que para la expresión novelada que empleaba, no requería de verificaciones documentales. Pero también se rumoreaba de que lo hacía para evitar plagios, deshonestidad que él denunció en algunas oportunidades calificando a dicho fenómeno como "una enfermedad nacional".

Y no obstante de que el ilustre catedrático de San Marcos vio y leyó documentos referentes a ciertas etnias que auxiliaron a los conquistadores en calidad de aliadas para luchar contra los incas hasta aniquilarlos, no les dio importancia. Así, no le fueron desconocidos los legajos de las informaciones de los curacas huancas (1560-1561) y 326 
de la hija y yerno de Contarhuacho, cacica de Ananhuaylas, aparte de otros testimonios dados por Pedro Sancho (1534), quien llegó a sostener que sin la ayuda de los "indios amigos", o sea de los aliados indígenas, jamás hubieran podido apoderarse del Perú en un tiempo tan corto y en forma tan fácil. No sabemos, pues, por qué Porras no otorgó el valor merecido a tan notables fuentes documentales. De manera que sencillamente arguye que el triunfo hispano se debió a la intrepidez de Pizarro en Cajamarca y en toda la campaña conquistadora. Con lo cual, según su discernimiento, ponía en el tapete una vez más su idealismo y subjetivismo.

Para Porras las causas de la caída del imperio Inca estuvieron determinadas también por la decadencia moral a que había devenido su clase dominante y dirigente.

Pero sea lo que fuere, la crítica considera que despues del estudio de Prescott el mejor volumen referente a Pizarro es el de Porras Barrenechea. Verdaderamente este historiador es quien más ha escundriñado acerca del caudillo de la conquista del Perú. Sin duda, es el texto más artístico de las biografías de Pizarro, al que él llamó "el fundador del Perú moderno".

\section{Aciertos y desaciertošblioteca de Letras}

Pero aparte de "lo expuesto, los trabajos de Porras sobre Pizarro, en general, deshicieron no todos pero sí una gran cantidad de errores hasta entonces de moda, propalados por los escritores indigenistas desde el siglo XIX. Vamos a enumerarlos:

$1^{\circ}$ Destruyó el mito del Pizarro expósito y porquerizo.

$2^{\circ}$ Dejó malparados a Alonso Enríquez de Guzmán y a Francisco de Gómara por haber originado la leyenda negra sobre el nacimiento e infancia de Pizarro. Lo mismo a Las Casas, por fanático y obsesivo; y a Antonio de Herrera por plagiario.

$3^{\circ}$ Rectificó al historiador extremeño vizconde de Amaya, quien en su libro Francisco Pizarro (1928) dio como fecha del nacimiento de su biografiado el 16 de mayo de 1468 . Porras descubrió que fue 10 años más tarde: en 1478 . 
$4^{\circ}$ Ubicó la casa en la que vino al mundo Francisco Pizarro en Trujillo de Extremadura, en un arrabal, junto al campo, y no en la casa solariega de los Pizarro, como inexactamente aparece en una fotografía que acompaña al volumen editado en 1978, publicado por Luis Alberto Sánchez,

$5^{\circ}$ Aclaró muchos aspectos sobre los progenitores del conquistador del Perú.

$6^{\circ}$ Descubrió que Pizarro, antes de venir a Santo Domingo, estuvo en Italia con el Gran Capitán.

$7^{\circ}$ Dilucidó el año en que Pizarro arribó a la isla Santo Domingo, en 1502, juntamente con Bartolomé de las Casas. Así, corrigió a los historiadores anteriores, entre ellos Ballesteros, que sostenían que fue en 1504.

$8^{\circ}$ Aclaró que en el contrato de Panamá no hubo comunión de una sola hostia, sino que fue en el Cusco algunos años despues.

$9^{\circ}$ Reveló que fue el licenciado Gaspar de Espinosa el que financió el segundo viaje.

$10^{\circ}$ Clarificó de Martinillo fue el intérprete de Valverde en la plaza de Cajamarca, y no Felipillo, quien sólo después adquirió importancia, especialmente en el groceso contras A tahualpa,

$11^{\circ}$ Elucidó en que fue Gómaráneni1552y elscreador de la leyenda del Felipillo urdidor de la trama para procesar a Atahualpa. Porras asegura que fueron Almagro y Riquelme los verdaderos instigadores. Y que el proceso fue hecho por los rumores de que el inca preparaba un ejército para destruir a los españoles.

$12^{\circ}$ Puso al descubierto al autor de la crónica anónima de 1534 , identificándolo con Cristóbal de Mena.

$13^{\circ}$ Descubrió el acta de la fundación española del Cusco.

$14^{\circ}$ Por igual, encontró la fecha de la fundación española de Jauja.

$15^{\circ}$ Identificó San Gallán con Pisco. Y

$16^{\circ}$ Puso en claro que la correcta pronunciación es Lima y no Rímac.

En este mismo rubro hay que mencionar cómo Porras dirigió la confección de un retrato de Pizarro. Es lienzo de dimensiones regula328 
res, donde se ve a un hombre con aspecto de haber pasado los 60 años de edad. Exhibe un cuerpo de entereza viril, erguido, bien que algo escuálido, con la barba blanca y atavíos negros, con sólo la cruz roja de Santiago al pecho. Lleva sombrero y un puñal a la diestra. Aparece no con los zapatos de piel de venado que habitualmente usaba, sino con alpargatas, que por entonces constituían muestras de gala y bravosidad entre los milicianos. Y por último porta la lujosa capa de marta que le había regalado Hernán Cortés, y que Pizarro se la ponía raras veces, apenas en los acontecimientos solemnes. Como se ve, Porras lo hizo retratar al estilo del Gran Capitán Gonzalo Fernández de Córdoba.

Es lamentable que en la edición de 1978, y en las otras también, los editores no hayan tenido la idea de dar a luz dicho lienzo, que por haber sido pintado bajo la mirada atenta de Porras es la efigie que más se aproxima al talante y fisonomía del conquistador del Perú. ciones:

Pero a diferencia de sus aciertos anteriores, hay otras incorrec-

$1^{\circ}$ Sostiene que la destrueción del Tahuantinsuyo fue favorecida por la decadencia y la corrupción moral de la clase dirigente incaica, a la que thana "casta ociosa y viciosa" sustentada por el trabajo de los "dyflus. A "Fo quie adicionar Sha" pugna por el poder entre Huáscar y Atahualpa. E idénticamente a la falta de previsión de Huayna Cápac para nombrar un sucesor y al odio entre las panacas. En este aspecto esquivó el rol que cumplieron los aliados indígenas.

$2^{\circ}$ Llama "bastardo" a Atahualpa, de seguro por desconocer las reglas de sucesión andinas, donde nunca hubo la noción la "bastardía". Además, le creyó nacido en Quito.

$3^{\circ}$ Da el calificativo de "hechicero" al sumo sacerdote de Pachacámac.

$4^{\circ}$ Del status de "esclavos" a los yanaconas.

$5^{\circ}$ Propugna que el incario configuró una confederación de naciones, con una estructura económico-social de carácter feudal. 
$6^{\circ}$ Acepta a Garcilaso al traducir Sacsaihuamán como "sáciate halcón" o "maíz puntiagudo", no obstante que el mismo Porras en otros escritos suyos reveló que la genuina traducción es "águila real".

$7^{\circ}$ Muchas palabras quechuas están confundidas en sus pliegos. Puede ser que se trate de fallas del linotipista. Verbigracia, por poner tambo de Chacamarca figura Chocamarca unas veces y Cachamarca en otras. Llama Pucará al asiento de Paucará.

$8^{\circ}$ Nombra Quioché al Quinche; Cayambo a Cayambe; Purataco a Puritico. Y así por el estilo.

$9^{\circ}$ Admite que Cuismancu y Chuquimancu estuvieron en Lima y Cañete, respectivamente. Ahora se sabe que correspondieron a la gran etnia de Cajamarca.

$10^{\circ}$ Dice que la llacta de Xauxa estaba atravesada por el río Mantaro, dato ilusivo similarmente, por cuanto dicho asentamiento urbano permanecía en su totalidad en la margen izquierda.

$11^{\circ}$ En lo que concierne al nombre de pila de Atahualpa y fecha de su agarrotamiento, Porras profiere que el padre Valverde lo bautizó con el nombre de Juan y que pasó a mejor vida el 24 de junio de 1533. No-mencionas sul fuentes pero la citada referencia equivocada es de Juan de Yelasco Ahora se, conoce, gracias a las informaciones que dejaron los propios hijos y nietos de Atahualpa, que su nombre fue Francisco en homenaje a su padrino Francisco Pizarro. Mientras que otros documentos exhumados por Rafael Loredo constatan que su muerte fue el 26 de julio de 1533.

$12^{\circ}$ Porras da crédito al Inca Garcilaso en lo que atañe a la batalla de Tocto, donde Tito Atauchi, dice, derrotó y capturó a 8 españoles. Hecho que hasta hoy no se ha comprobado, motivo por el cual aquella presunta contienda no figura en ningín libro moderno referente a la conquista del Perú.

$13^{\circ}$ Porras no especifica qué indios le hacían la guerra a Pizarro cuando éste marchaba al Cusco. Apunta "los indios" en general y nada más. Lo cierto es que solamente se trataba de las tropas de Atahualpa comandadas por Quisquis. 
$14^{\circ}$ Asevera que el franciscano fray Marcos de Niza apenas llegó hasta Quito. Pero otros papeles permiten afirmar que estuvo incluso en Pachacámac. Exacto, aparece aquí en una relación de gente que pertenecía a las tropas de Pedro de Alvarado. Por consiguiente Pizarro y Almagro conocieron a Niza. De todas maneras el aludido fraile no estuvo en Cajamarca durante la prisión de Atahualpa, como lo pregona falsamente fray Bartolomé de las Casas. Y

$15^{\circ}$ Expresa que Manco Inca perdió en el sitio de Lima, víctima de su fatalismo. Olvidando así que su derrota estuve decidida por los auxiliares huaylas, huancas y cañares que apoyaban a los españoles.

\section{Porras, romántico pero peruanista}

Raúl Porras Barrenechea, como lo calificó Lohmann, fue un historiador romántico, con un regusto exquisito para trazar biografías de corte narrativo, anecdótico y hasta novelesco, acompañado de vez en cuando de jugosas explicaciones sobre la sicología de sus personajes, como Pizarro, Almagro, Atahualpa, etc, En algunas ocasiones me da sensación de haber sacrificado la autenticidad de los acontecimientos en aras de la belleza de la frase. Pero lo que sí se capta con nitidez es que preseindio de 9 tas multitudes humanas en

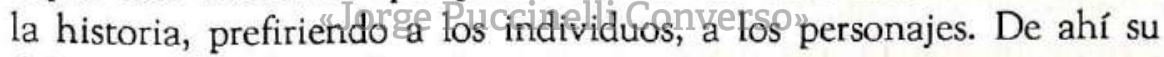
deleite por las biografías.

Se advierte, asimismo, que era muy imaginativo. A base de un sólo dato generaba vívidas escenas que sus oyentes y lectores aceptaban como si hubieran ocurrido realmente. El manifestaba que eran deducciones lógicas.

Y si bien sabía conjeturar sobre sucesos que los documentos no diafanizaban con precisión, lo verídico es que nunca abusaba de su imaginación. De manera que en sus escritos raramente surgen palabras como "parece", "tal vez", "quién sabe", "es posible" y otras equivalentes que hoy son rutinarias, hasta causar fatiga, entre algunos historiadores. El punto en el que más imaginó Porras fue en lo que pensaría Atahualpa en Cajamarca. Al respecto presumió muchas cosas contra el referido inca. Sostiene que Pizarro incumplió el pacto del rescate 
porque el soberano andino planeaba atacarlo, ocurrencia que no ha sido probada.

Hay una etapa en la que podemos decir que en Porras predominaba en forma abierta su hispanismo. Prácticamente hasta mediados de la década del '40, para pronto dar inicio a sus análisis del alma andina. Recordemos que en el enunciado decenio fueron intensificadas las excavaciones arqueológicas y apareció entre nosotros la etnohistoria, disciplinas que revolucionaron los conocimientos atingentes a las culturas y civilizaciones prehispánicas. Con toda seguridad, eso motivó el cambio de las reflexiones del distinguido biógrafo de Pizarro, acabando no como hispanista ni indigenista, sino como peruanista.

Es incontrovertible que la inclinación de Porras fue la conquista y en segundo plano el virreinato y la emancipación, épocas sobre las cuales dejó bastantes publicaciones. Pero lo incaico también formó parte de sus conocimientos, ya que su concepción totalizante de la historia no podía mantenerlo alejado de ninguna etapa clave de la identidad nacional.

De modo que fue en 1951 que comenzó el Porras peruanista. Fue el año en que leyó y publicó su intenso ensayo rotulado Mito, tradición e historia en el Perú, remontandose a los más vetustos tiempos de la civilización andina, a la que enálteció y ponderó con inmenso encanto y franqueza. A la misma época pertenece su trabajo erudito concerniente al Quipu y la quilca. Su actitud peruanista también ha quedado perennizada en su esfuerzo para editar los más trascendentales diccionarios y gramáticas quechuas de los siglos XVI y XVII (Domingo de Santo Tomás y Diego González Holguín). Análogamente él fue quien incentivó y logró la financiación para que Guillermo Escobar Risco pudiera realizar la sexta edición del Vocabulario quichua de 1584. En 1953 concluyó su profundo ensayo El Ollanta y en 1955 su extraordinario trabajo acerca de la Epica y la poesía incaica, cuya lectura hecha por él mismo asombró a los oyentes que asistieron a escucharlo en la ANEA de Lima.

También demostró su sincera peruanidad, entendida ésta como la síntesis de los legados andinos e hispanos en dos libros más: la 332 
Pequeña antología de Lima y la gran Antología del Cuzco. El primero sobre la capital virreinal y republicana; y el otro relativo del asentamiento urbano de neta raigambre inca, al que, tan igual que Riva-Agüero, lo consideró el corazón y la yema del Perú.

Cuando yo era alumno de Porras, él era ya un peruanista cabal. Es decir, un buen admirador de lo mejor de la herencia española y andina.

Por consiguiente, aquí es aconsejable reiterar de que no obstante ser un exuberante panegirista de Pizarro y de la obra colonizadora de España, a Porras no se le puede tildar de imperialista, ni tampoco de rabioso hispanista. El fue, antes que nada, peruanista. Su antiimperialismo quedó patentizado en 1960 cuando, como ministro de Relaciones Exteriores, se negó a firmar el documento que condenaba a Cuba a un injusto bloqueo. El discurso que pronunció al respecto es célebre por los principios sostenidos en él acerca de la no intervención y el derecho de los pueblos a determinarse por sí mismos.

Y si bien el Pizarro đe Porras es la más egregia biografía del conquistador, muchos seguimos pensando que su libro cumbre es las Fuentes históricas peruanas (1955) y en seguida sus Cronistas del Perú (1962), en el que identificó a varios anónimos y descubrió a otros. Ambos volúmenes, rebosantés dedectes dapítulos gscon un tenor de fina estética literaria. "Jorge Puccinelli Converso"

Es que Raúl Porras, historiador peruano nacido en Pisco (1897) en un hogar pobre pero aristócrata, ha sido en el siglo xx el mejor estudioso de las fuentes históricas peruanas, incluyendo a los cronistas de los siglos XVI y XVII.

\section{Su obra trunca}

Tanto en su testamento (1954) como en sus Fuentes históricas (1955) declara que su biografía de Pizarro estaba aún inconclusa. Y anuncia que fragmentos de los que hasta entonces tenía escrito habíalos publicado en distintas revistas. Sin embargo, abrigaba esperanzas de terminarla. Y prueba de ello es que a las clases de Conquista y colonia, que corrían a su cargo en San Marcos, nos llevaba para mostrarnos docenas de papeles y un cúmulo de bellísimos grabados, fotografías y 
mapas con los que meditaba ilustrar la edición de lo que él juzgaba su obra magna. Es una lástima que Luis Alberto Sánchez no los tomará en cuenta para la edición de 1978.

Los que fuimos sus discípulos podemos dar fe que poseía varios y grandes fólderes de documentos transcritos, listos para publicar. Eran cuadernos conteniendo copias mecanografiadas de cartas, cedularios y reales provisiones concediendo encomiendas desde Pizarro a La Gasca, informaciones de servicios, memoriales de conquistadores y otros escritos. Incansablemente nos hablaba sobre la necesidad urgente de darlos a conocer para reconstruir sin omisiones la historia de la Conquista. De todo ello escasamente salieron a la luz un volumen de Cartas del Perú y los dos del Cedulario en la serie Colección de documentos inéditos para la historia del Perú (1959/1960), quedando inédito lo restante.

Con todo, cabe anotar aqui que en el libro de Cartas del Perú: 1524-1543 faltan algunas que posteriormente las publicó Guillermo Lohmann. Los que a Porras les quitaron tiempo, no dejándole espacio para culminar sus proyectos, fueron la docencia universitaria, las conferencias continuas que daba y más que todo sus actividades políticas y la inacabable afluencia de alumnos y amigos que sin cesar y diariamente tocaban la puetraidetsucasalen lacalle Colina de Miraflores, unos para visitarle, oțos pafauconsaltáfle yotros" para escucharle, no faltando algunos que iban en pos de influencia y prestigio bajo su sombra.

Porras, además, no acostumbraba escribir él msmo, sino que dictaba a sus ayudantes. Todo lo hacía con esta modalidad, incluso los informes que emitía sobre las tesis de grado de sus alumnos. Eso ocurrió conmigo, cuyo informe, justamente, le hizo copiar a Mario Vargas Llosa.

Y por fin, como dice Edmundo Bendezú, el mejor mensaje de Porras a las nuevas generaciones de historiadores peruanos es su sacrificio y desvelo para elevar el nivel de los estudios históricos en nuestro país, para encontrar la certeza de los hechos con perfección e integridad. Este es el ejemplo que dio Porras en su cátedra de San Marcos y en sus obras publicadas en el Perú y España. 


\section{ADDENDA. Recuerdos personales}

Conocí a Raúl Porras en 1951, año del cuatricentenario de la Universidad Mayor de San Marcos. No personalmente, sino a través de una serie de conferencias y artículos alusivos a tal acontecimiento, publicados en las páginas culturales de los grandes rotativos limeños de entonces. Claro que dichos periódicos llegaban con uno o dos días de retraso a Cajamarca, salvo en las fechas en que los aviones de la Faucett cumplían con sus vuelos a la citada ciudad.

Pero a partir de 1953 tuve la suerte de ser uno de sus alumnos en las aulas sanmarquinas. Ahí, desde el primer momento nos impactó su inmenso y luminoso saber humanístico, su dicción elegantísima, su agilidad y claridad expositiva sin mácula, su madurez magistral, sus altas calidades como investigador de la historia y literatura. Es que manejaba con seguridad extraordinaria a las fuentes, a la par que con hábil sentido crítico a los documentos, analizándolos con cuidada actitud científica. Sus clases sobre límites del Perú constituían genuinas cátedras de peruanidad. Nuestro pais, deeía es una patria muy antigua, con milenios de existencia, cuyas raíces profundas arrancan en las remotas épocas del paleolítico andino, enriquecida siglos más tarde con el desarrollo civilizador de los propios peruanos; y ulteriormente con los aportes traídos por los thispanos a qutenesadmiraba. Todo ello deslumbraba y no cansabacescucharlè horas tras horas. Ningún oyente dormía ni bostezaba, pese a que sus disertaciones las hacía de 12 del día a 2 p.m. Es que Porras vivía el pasado, recreándolo con vigor y fidelidad.

Así fue como, muy pronto descubrimos al maestro completo: bondadoso, cordial, muy exigente con las lecturas e interpretación de textos y con los exámenes que tomaba invariablemente orales, jamás escritos. En fin, un auténtico amigo de sus amigos.

No lo visitaba con frecuencia, como sí ocurría con otros de sus discípulos. Pero cada que iba siempre lo hallaba rodeado por Pablo Macera, Carlos Araníbar, Federico Kauffmann, Hugo Neira y a veces por Mario Vargas Llosa.

La última vez que vi a Porras fue en el 22 de agosto de 1958, la víspera de mi viaje al Archivo de Indias (Sevilla/España), gracias a 
una beca gestionada justamente por el insigne maestro. Su generosidad fue tan enorme que tuvo la infinita afectuosidad de regalarme tres de sus sueldos que percibía como docente sanmarquino, como un complemento económico para cuando arribase a Barcelona y Madrid. Fue un gesto inolvidable (por eso uno de mis libros: La destrucción del imperio de los incas [1973] lo dediqué a su memoria).

Cuando retorné en 1962, Porras ya no estaba en San Marcos. El formidable maestro de la civilización peruana había finado dos años antes. Fue un vacío que sentimos todos, por la sencilla razón, como lo expresó alguna vez P. Macera, de que con su fallecimiento también murió algo de nosotros mismos, algo del Perú y de Hispanoamérica. Pero han quedado sus obras, sus alumnos y sus verdaderos amigos que lo recuerdan año tras año.

BIBLIOGRAFIA BASICA

Arciniega, Rosa

1936 Pizarro. Biografía del conquistador del Perú. Madrid, Editorial Genitioteca de Letras

Ballesteros Gaibrois, IManuiekinelli Converso"

1963 Descubrimiento y conquista del Perú. Barcelona, Salvat Editores.

Bendezú Aibar, Edmundo

1992 Literatura, historia e ideología en la biografía de Francisco Pizarro. Lima, Editorial Lumen.

BERMEjo,Vladimiro

1942 Vida y hechos del conquistador del Perú don Francisco Pizarro. Arequipa.

Busto, José Antonio del

1965 Francisco Pizarro, el marqués gobernador. Madrid, Ediciones Rialp. 
Cuneo VIDal, Rómulo

1925 Vida del conquistador del Perú don Francisco Pizarro y de sus hermanos Hernando, Juan y Gonzalo Pizarro y Francisco Martín de Alcántara. Barcelona, Casa Editorial Maucci.

Hemming, John

1970 The conquest of the incas. London, Macmillan.

Lohmann Villena, Guillermo

1986 Francisco Pizarro. Testimonio: documentos oficiales, cartas y escritos varios. Madrid, Monumenta Hispano-Indiana.

Porras Barrenechea, Raúl

1941 Homenaje a Francisco Pizarro. Lima, Gil. Impresores.

1954 Fuentes históricas peruanas. Lima, P.L. Villanueva Editores.

1965 Pequeña antologia de Lima. El río, el puente y la alameda. 2a. edición. Lima, Instituto Raúl Porras Barrenechea.

1978 Pizarro. Prólogo de Luis Alberto Sánchez. Lima, Editorial Pizarro.

Prescott, Guillermßiblioteca de Letras

1853 Historiá Ide' Ea conquistal del Pertéén'observaciones preliminares sobre la civilización de los incas. Madrid, Imprenta y Librería de Gaspar Roig, editores.

RuIz, Felipe G.

1945 Pizarro. (El Perú prehispánico y la Conquista). 2a. ed. Madrid, Ediciones Morata. 